\title{
Steam treatment of contaminated groundwater aquifers - development of pathogenic micro-organisms in soil
}

\author{
Carsten Suhr Jacobsen, Susanne Elmholt, Carsten Bagge Jensen, Pia Bach Jakobsen \\ and Mikkel Bender
}

Steam treatment of contaminated soil and aquifer sediment is a promising method of cleaning soil. The treatment is based on steam injection into a water saturated porous aquifer (Gudbjerg et al. 2004), by which the heat transfers the contaminants into the vapour phase, allowing entrapment in an active carbon filter connected to a large vacuum suction device. The treatment is effective against several important groundwater contaminants, including pentachlorophenole and perchloroethylene, typically found in association with industrial processes or dry cleaning facilities. Furthermore, as an example of removal of non-aqueous phase liquids (NAPLs) large amounts of creosote have been recovered after steam injection in a deep aquifer (Kuhlmann 2002; Tse \& Lo 2002).

Steam treatment is dependent on the complete heating of the soil volume under treatment. The steam has a strongly adverse impact on trees and other plants with deep root systems within the soil, but no other visible effects have been reported. The aim of the activities undertaken during collaborative projects carried out by the Geological Survey of Denmark and Greenland (GEUS) and the Danish Institute of Agricultural Sciences (DJF) for the Danish Environmental Protection Agency and the local authorities in Copenhagen (Københavns Amt) was to establish to what extent the microbial community was affected by the steam treatment of the soil. A few results from the literature indicate that the microbial activity increases in steam treated soil (Richardson et al. 2002), probably due to microbial degradation of the soil contaminants in combination with microbial utilisation of heatkilled organisms.

It is, however, not known whether this increased microbial activity is associated with the development of pathogenic micro-organisms; these are typically able to grow at higher temperatures than the general microbial community in soil.

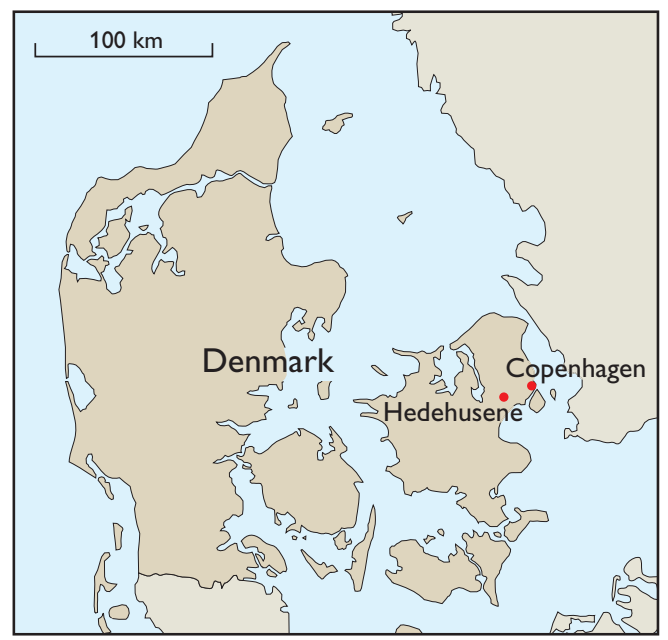

Fig. 1. Sketch of steam treatment facility at a strongly contaminated industrial site at Hedehusene, west of Copenhagen. Inset map shows location.

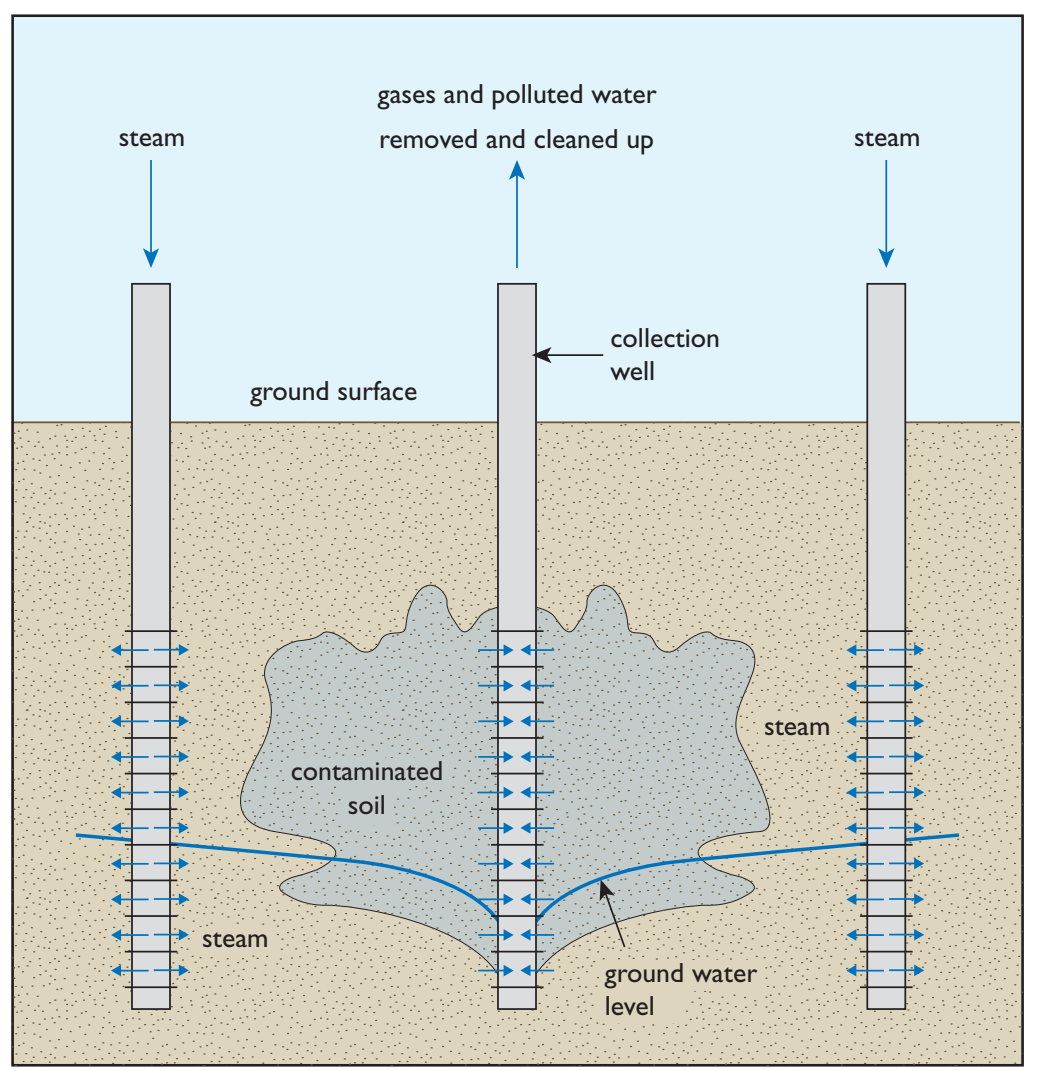



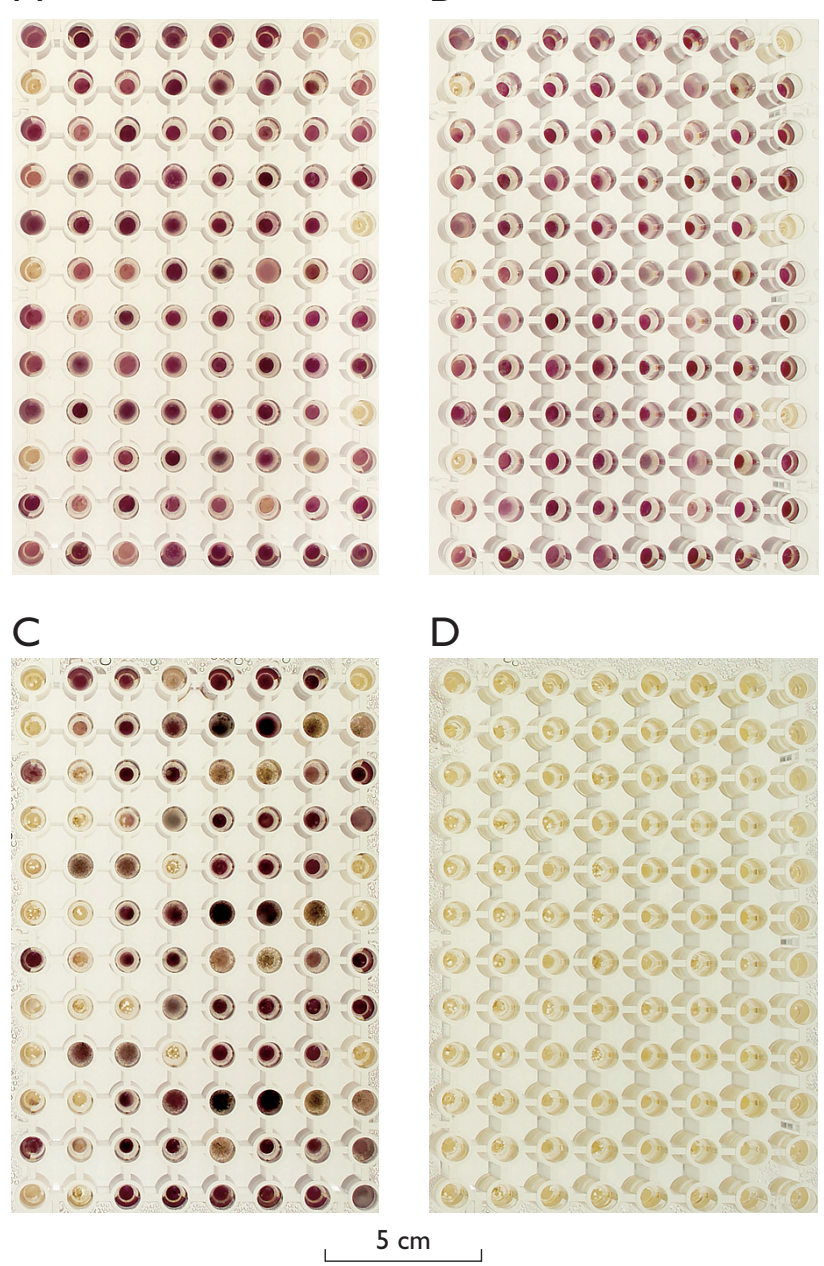

Fig. 2. Changes of microbial metabolic fingerprints using comparisons of the ability of micro-organisms to grow on different carbon substrates. The appearance of coloration in each section indicates growth of microorganisms. A high number of positive sections at $42^{\circ} \mathrm{C}$ indicate a high number of organisms able to grow at temperatures associated with pathogenic micro-organisms. A: steam-treated soil with growth at $20^{\circ} \mathrm{C}$. B: control soil with growth at $20^{\circ} \mathrm{C}$. C: steam-treated soil with growth at $42^{\circ} \mathrm{C}$. D: control soil with growth at $42^{\circ} \mathrm{C}$.

\section{The steam treatment in Hedehusene}

Hedehusene is situated approximately $25 \mathrm{~km}$ to the west of Copenhagen, and the contaminated soil and groundwater aquifer here results from various industrial activities primarily carried out between 1920 and 1970. These activities include a dry cleaning facility and several small workshops. From both types of industry, trichloroethylene and tetrachloroethylene are often found as groundwater contaminants. The groundwater aquifer in Hedehusene was known to be contaminated with high concentrations of trichloroethylene, which has been a constant hazard to an important drinking water production well downstream from the site.
Pumping, treating and recycling water at the site over many years had controlled the distribution of the contamination, but the main contamination was still present at very high levels and has become a long-term threat to continued groundwater extraction.

The steam treatment in Hedehusene was carried out during the winter 2001-2002. Wells delivering steam were buried nine metres below the land surface, allowing the transfer of steam below the contamination plume (Fig. 1). The steam was pumped continuously for a period of five months, until the temperature reached $90^{\circ} \mathrm{C}$. Heating of the soil allowed the transfer of the contaminant to the vapour phase which was then trapped in an active carbon filter.

\section{Heat-tolerant micro-organisms found at the Hedehusene site}

The site was monitored by sampling surface soil and soil from approximately $50 \mathrm{~cm}$ depth on 11 September 2001 (before the steam treatment), and resampling during and after the steam treatment. Sampling was undertaken six times with the latest sampling on 26 October 2004. In general, it was found that the number of heat-tolerant micro-organisms increased after the heat treatment, and that some of the heat-tolerant micro-organisms could still be found three years after the 2001-2002 steam treatment.

Heat-tolerant bacteria are defined as able to continue growing at temperatures of $42^{\circ} \mathrm{C}$, and heat-tolerant fungi as those able to continue growing at $37^{\circ} \mathrm{C}$. Such high temperatures do not occur naturally at the site, and soil micro-organisms originating from this site are not expected to be able to grow at such high temperatures. Heat tolerance is one of the main characteristics that distinguish normal soil microorganisms from pathogenic micro-organisms found in human patients.

\section{General microbial community adaptation to growth at high temperature}

The effect on the general microbial community was investigated by assessing its growth rate on 24 different microbial food sources. A small amount of soil was added to 24 different microbial growth media and incubated at either $20^{\circ} \mathrm{C}$ or $42^{\circ} \mathrm{C}$. This technique revealed that the microbial community in the control plot was very constant in its ability to utilise the different food sources during the sampling period. Furthermore, the microbial community in the control plot showed little ability to utilise food sources at the elevated temperature (an area approximately $30 \mathrm{~m}$ away from the heating zone). In contrast, the heated soil showed a massive and long-lasting 


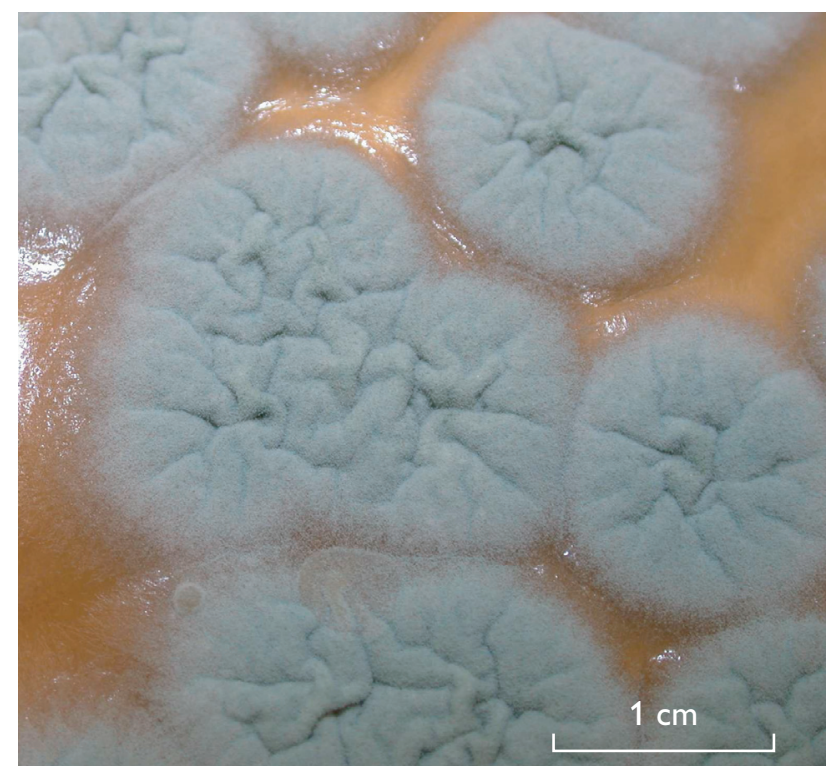

Fig. 3. Colony of Aspergillus fumigatus isolated from steam-treated soil.

increase in the ability of the microbial community to utilise the food sources at $42^{\circ} \mathrm{C}$ (Fig. 2).

It is well known that micro-organisms differ in their ability to survive in soil. Some are able to form spores that can stay inactive in the soil for years while others die out due to predation and competition with micro-organisms having a very low level of metabolic activity. We have chosen two different representatives of heat-tolerant micro-organisms: a bacterium without the ability to form spores, and a fungus which forms conidia. Although these conidia are able to germinate and grow in the laboratory, they need not be active in the soil. Both species showed a clear response to soil heating as described below.

\section{Aspergillus fumigatus - an unusual pathogenic and allergenic micro-organism}

Aspergillus fumigatus is a remarkable and unusual pathogen because in addition to causing life-threatening invasive disease of immuno-compromised human patients, it can also cause allergic reactions in persons with fully functional immune systems (Latgé 1999; Denning et al. 2002).

A. fumigatus is easily identified and is distinguished by rapidly growing colonies in characteristic turquoise to dark green colours, by the phialides curving to be roughly parallel to each other and to the axis of the stipe, and the presence of small conidia in columns (Fig. 3; Klich \& Pitt 1988). A. fumigatus is regularly reported as a dominant species in vari- ous types of compost, but never as a dominant species in soil (Domsch et al. 1993).

$A$. fumigatus was only found in very low numbers in the untreated control plot, but in the heat-treated soil this fungal species was abundant. A. fumigatus was still present in elevated numbers at the last sampling in October 2004 in the heat-treated soil, but the numbers were slowly declining. It seems, however, likely that the elevated numbers of $A$. fumigatus will continue for some time due to the ability of the fungus to form conidia.

\section{Pseudomonas aeruginosa - an opportunistic pathogen}

Pseudomonas aeruginosa is an opportunistic pathogen, meaning that it exploits any defects in the human host defences to initiate an infection. It causes urinary tract infections, respiratory system infections and also bone and joint infections. Furthermore, it is associated with gastrointestinal infections and a variety of systemic infections, particularly in patients with severe burns and in immuno-compromised cancer and AIDS patients. P. aeruginosa infections are a serious problem for patients hospitalised with cancer, cystic fibrosis and burns. The case fatality rate for these patients is $50 \%$.

$P$. aeruginosa increased from non-detectable (less than 100 cells per gram of soil) in the non-treated soils to $10^{5}$ cells per gram of soil in the heat-treated soil (Fig. 4). P. aeruginosa is a

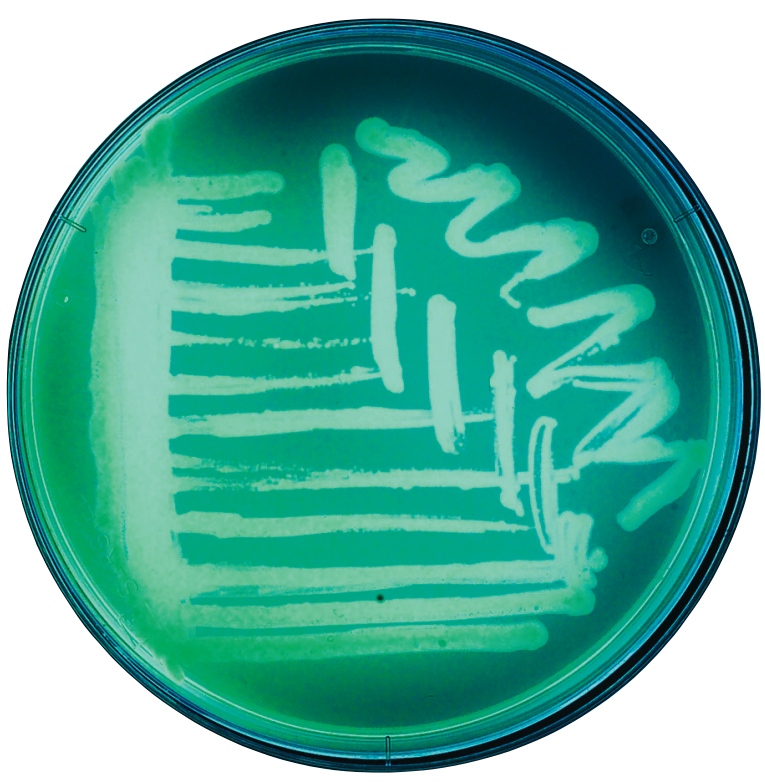

Fig. 4. Pseudomonas aeruginosa isolated from steam-treated soil. The photograph was taken in ultraviolet light to show the characteristic fluorescence of this bacteria genus. Diameter of view is $9 \mathrm{~cm}$. 
representative of fast growing soil bacteria that are unable to form spores. In contrast to $A$. fumigatus, the population of $P$. aeruginosa decreased rapidly after the heat treatment, and after one year the numbers were again below the detection level. This reduction was probably due to predation and lack of competing abilities when the temperature decreased.

\section{Need for monitoring of microbial side- effects in relation to steam treatment}

Micro-organisms differ in their ability to develop resting forms. A. fumigatus develops conidia that can remain in soil for many years. These resting conidia may not be active in the soil, even if they can be detected on agar plates when analysed in the laboratory. In contrast, $P$. aeruginosa does not form resting spores, and detection on agar plates in the laboratory is connected to activity of the bacterium in the soil.

The present project highlights the need for microbial risk assessments in connection with new steam treatment projects. The high level of potentially pathogenic micro-organisms expected after heat treatment of a soil points to the need for monitoring these organisms in connection with new steam treatment projects.

\section{References}

Denning, D.W., Anderson, M.J., Turner, G., Latgé, J.-P. \& Bennett, J.W. 2002: Sequencing the Aspergillus fumigatus genome. The Lancet Infectious Diseases 2, 251-253.

Domsch, K.H., Gams, W. \& Anderson, T.-H. 1993: Compendium of soil fungi 1, 2, 2nd edition, 860 pp., 406 pp. Eching: IHW-Verlag.

Gudbjerg, J., Trotschler, O., Farber, A., Sonnenborg, T.O. \& Jensen, K.H. 2004: On spurious water flow during numerical simulation of steam injection into water-saturated soil. Journal of Contaminant Hydrology 75, 297-318

Klich, M.A. \& Pitt, J.I. 1988: A laboratory guide to the common Aspergillus species and their teleomorphs, 116 pp. North Ryde, Australia: CSIRO Division of Food Processing.

Kuhlman, M.I. 2002: Analysis of the steam injection at the Visalia Superfund Project with fully compositional nonisothermal finite difference simulations. Journal of Hazardous Materials 92, 1-19.

Latgé, J.-P. 1999: Aspergillus fumigatus and Aspergillosis. Clinical Microbiology Reviews 12, 310-350.

Richardson, R.E., James, C.A., Bhupathiraju, V.K. \& Alvarerez-Cohen, L. 2002: Microbial activity in soils following steam treatment. Biodegradation 13, 285-295.

Tse, K.K.C. \& Lo, S.-L. 2002: Desorption of PCP-contaminated soil: effect of temperature. Water Research 36, 284-290.

\section{Authors' addresses}

C.S.J., P.J. \& M.B., Geological Survey of Denmark and Greenland, Øster Voldgade 10, DK-1350 Copenhagen K, Denmark. E-mail: csj@geus.dk

S.E., Danish Institute of Agricultural Sciences, Blichers Allé 20, DK- 8830 Tjele, Denmark.

C.B.J., Copenhagen County, Soil and Groundwater Department, Stationsparken 27, DK-2600 Glostrup, Denmark. 